\title{
MicroRNA-101 inhibits autophagy to alleviate liver ischemia/reperfusion injury via regulating the mTOR signaling pathway
}

\author{
HU SONG ${ }^{1,2^{*}}$, CHENYANG DU $^{1,2^{*}}$, XINGXING WANG ${ }^{1,2^{*}}$, JIANJUN ZHANG $^{1-4}$ and ZHONGYANG SHEN ${ }^{1-4}$ \\ ${ }^{1}$ First Central Clinical College, Tianjin Medical University, Tianjin 300070; \\ ${ }^{2}$ Tianjin Key Laboratory for Organ Transplantation; ${ }^{3}$ Liver Transplantation Department, Tianjin First Center Hospital; \\ ${ }^{4}$ Key Laboratory of Transplant Medicine, Chinese Academy of Medical Sciences, Tianjin 300192, P.R. China
}

Received September 8, 2018; Accepted January 17, 2019

DOI: $10.3892 / \mathrm{ijmm} .2019 .4077$

\begin{abstract}
Liver ischemia/reperfusion injury (LIRI) is a common complication of liver surgery, and affects liver function post-transplantation. However, the precise mechanism underlying LIRI has not yet been completely elucidated. Previous studies have demonstrated the involvement of a number of microRNAs (miRNAs/miRs) in liver pathophysiology. The objective of the present study was to determine the potential function and mechanism of miR-101-mediated regulation of autophagy in LIRI. Compared with the sham-treated group, a significant decrease in miR-101 and mechanistic target of rapamycin (mTOR) expression levels following ischemia/reperfusion (IR) were observed, along with an increased number of autophagosomes $(\mathrm{P}<0.001)$. The exogenous overexpression of miR-101 has been demonstrated to inhibit autophagy during the LIRI response and the levels of mTOR and phosphorylated (p)-mTOR expression are correspondingly elevated. However, compared with the miR-NC group, miR-101 silencing was associated with reduced mTOR and p-mTOR levels and increased autophagy, as indicated by the gradual increase in the levels of the microtubule-associated protein 1 light II (LC3II). The peak levels of LC3II were observed $12 \mathrm{~h}$ subsequent to reperfusion, which coincided with the lowest levels of miR-101. In addition, inhibition of autophagy by 3-methyladenine significant enhanced the protective effect of miR-101 against LIRI, compared with the IR group $(\mathrm{P}<0.001)$. Altogether, miR-101
\end{abstract}

Correspondence to: Professor Jianjun Zhang or Professor Zhongyang Shen, Liver Transplantation Department, Tianjin First Center Hospital, 24 Fukang Road, Tianjin 300192, P.R. China

E-mail: yzxzhangjianjun@163.com

E-mail: zhongyangshen@vip.sina.com

\section{${ }^{*}$ Contributed equally}

Key words: liver ischemia/reperfusion injury, autophagy, microRNA-101, mechanistic target of rapamycin attenuates LIRI by inhibiting autophagy via activating the mTOR pathway.

\section{Introduction}

Liver ischemia/reperfusion injury (LIRI) is a common complication in liver surgery, and substantially influences the surgical outcome and patient prognosis (1-3). In previous years, the shortage of transplantation donors has increased the prevalence of marginal donors that further increase the risk of LIRI, and subsequently that of primary graft insufficiency or post-transplantation dysfunction $(4,5)$. The mechanisms underlying LIRI pathology are highly complex and include the excessive production of reactive oxygen species, intracellular calcium overload, microvascular endothelial injury, inflammation and autophagy (6). It is essential to elucidate the exact molecular mechanism underlying LIRI, in order to protect the hepatocytes against ischemic injury.

Previous studies have revealed the involvement of microRNAs (miRNAs/miRs) in LIRI-associated autophagy (7-9). miRNAs are non-coding RNAs $21-23$ nucleotides long, and bind specifically to the 3'-untranslated region (3'-UTR) of the target mRNA, resulting in either mRNA degradation or a protein translation block $(10,11)$. miRNAs may additionally mediate the upregulation of target mRNAs by direct activation and/or indirect derepression to enhance mRNA stability and translational activation (12). miRNAs have been implicated in various cellular and molecular events, including proliferation, differentiation and apoptosis, and the dysregulation of miRNAs is the mechanistic basis of various pathophysiological conditions $(13,14)$. Previous studies have revealed a notable function of miR-101 in modulating autophagy. For example, Frankel et al (15) identified that miR-101 inhibited autophagy in breast cancer cells, whilst Valera et al (16) demonstrated that miR-101 induced multiple system atrophy via autophagy in the nervous system. In addition, Xu et al (17) concluded that miR-101 inhibited autophagy and enhanced cisplatin-induced apoptosis in hepatoma cells. The aim of the present study was to determine the function of miR-101 in mediating autophagy in LIRI, in order to identify a novel therapeutic target for LIRI. 


\section{Materials and methods}

Animals and cell lines. A total of 60 male C57BL/6 mice (7-8 weeks old, weighing 20-25 g) were obtained from the Experimental Animal Center of Academy of Military Medical Sciences (Beijing, China). All animals were maintained in an air-conditioned animal room at $25^{\circ} \mathrm{C}$ with free access to water and food, and exposed to a 12-h light/dark cycle. All animal experiments conformed to the National Institute of Health guidelines $(18,19)$, and the animals were treated humanely. The study passed the ethical review of the Tianjin First Center Hospital (Tianjin, China) for the use of experimental animals, and the protocols were ethically approved by the ethics committee of Tianjin First Central Hospital. The non-tumorigenic mouse hepatocyte acute myeloid leukemia (AML) 12 cell line was purchased from the Shanghai Cell Bank of Chinese Academy of Sciences (Shanghai, China).

Reagents and antibodies. Fetal bovine serum, 0.05\% trypsin-ethylenediaminetetraacetic acid and Dulbecco's modified Eagle's medium (DMEM)/F12 medium were purchased from Gibco (Thermo Fisher Scientific, Inc., Waltham, MA, USA). The miR-101 mimetics/inhibitor, miR-101 agomir/antagomir, miRNA negative control (miR-NC), and RiboFECTTM CP Reagent were purchased from Guangzhou RiboBio Co.,Ltd. (Guangzhou, China). Trizol and SYBR Green reverse transcription-quantitative polymerase chain reaction (RT-qPCR) Master Mix were purchased from Invitrogen (Thermo Fisher Scientific, Inc.) and Beijing Transgen Biotech Co., Ltd. (Beijing, China), respectively. The In Situ Cell Death Detection kit was purchased from Roche Diagnostics $\mathrm{GmbH}$ (Mannheim, Germany). An immunohistochemistry kit (cat. no. PV-9001) and DAB chromogenic kit (cat. no. ZLI-9018) were purchased from OriGene Technologies, Inc. (Beijing, China). The autophagy double-labeled adenovirus [m red fluorescence protein (RFP)-green fluorescence protein (GFP)-LC3] was acquired from Hanbio Biotechnology Co., Ltd. (Shanghai, China), and 3-methyladenine (3-MA) from Selleck Chemicals (Houston, TX, USA). Rapamycin (Rapa) and methylthiazole tetrazolium kit (MTT) were acquired from Sigma-Aldrich (Merck KGaA, Darmstadt, Germany). Antibodies against mechanistic target of rapamycin (mTOR; cat. no. 2972), phosphorylated (p-)mTOR (cat. no. 2971), caspase-3 (cat. no. 9662), sequestosome 1/p62 (cat. no. 16177), microtubule-associated protein 1 light II (LC3II; cat. no. 3868), proliferating cell nuclear antigen (PCNA; cat. no. 13110) and GAPDH (cat. no. 5174), and the horseradish peroxidase (HRP)-conjugated anti-rabbit (cat. no. 7074) and anti-mouse (cat. no. 7076) secondary antibodies were all purchased from Cell Signaling Technology, Inc., (Danvers, MA, USA).

Establishment of an in vivo model of LIRI. This experiment established a segmental (70\%) LIRI model according to a previous study (20), with the arterial and portal venous blood supply to the left and middle lobes interrupted using an atraumatic clip. Following 90 min of local ischemia, the clip was removed. Animals were sacrificed by dislocation of spine and harvested after 2, 6, 12 or $24 \mathrm{~h}$ reperfusion. Sham-operated mice underwent the same procedure, but without vascular occlusion as previous described (20). The mice were random- ized into the following 10 groups (n=6/group): A control/sham operated group, 4 untreated LIRI groups with different reperfusion times $(2,6,12$ and $24 \mathrm{~h})$ and 5 LIRI groups that were administered an intravenous injection $24 \mathrm{~h}$ prior to ischemia and harvested subsequent to $12 \mathrm{~h}$ reperfusion, with injections consisting of the following: i) $10 \mathrm{nM}$ miR-101 agomir, ii) $10 \mathrm{nM}$ miR-101 antagomir, iii) $10 \mathrm{nM}$ miR-NC, iv) $5 \mathrm{mg} / \mathrm{kg}$ 3-MA and v) miR-101 agomir plus 3-MA. The 3-MA was intraperitoneally administered $1 \mathrm{~h}$ prior to ischemia.

Serological tests. Blood was collected from the mice from their inferior vena cava and centrifuged $\left(4^{\circ} \mathrm{C}, 15 \mathrm{~min}, 1,000 \mathrm{x} \mathrm{g}\right)$ to collect the serum. The levels of serum aspartate aminotransferase (AST) and alanine aminotransferase (ALT) were determined using commercial assay kits (Nanjing Jiancheng Bioengineering Institute, Nanjing, China) and according to the manufacturer's protocol. Enzyme activity was expressed as international units per liter (U/I).

Hematoxylin and eosin $(H \& E)$ staining. The liver tissues were fixed in $4 \%$ formalin for $48 \mathrm{~h}$ at $4^{\circ} \mathrm{C}$, embedded in paraffin blocks and processed into $4-\mu \mathrm{m}$-thick sections. The slides were then dehydrated using an ethanol gradient $(100 \%$ for $10 \mathrm{~min}$, 95\% at $10 \mathrm{~min}$ and $80 \%$ for $10 \mathrm{~min}$ ) and de-paraffinized using xylene. H\&E staining was performed according to a standard procedure (21), and the histopathological changes were observed under a light microscope at a magnification of $\mathrm{x} 200$. IR-induced liver damage was quantified by measuring the Suzuki score as presented in Table I and a previous study (22).

Immunohistochemistry. Paraffin sections of liver tissue were cut into $4-\mu \mathrm{m}$-thick sections and dehydrated, cleared using xylene and heated to $95^{\circ} \mathrm{C}$ using $0.01 \mathrm{~mol} / 1$ citrate buffer solution (pH 6.0) in a water bath for antigen retrieval. Subsequent to blocking with 5\% goat serum (Solarbio Science \& Technology Co., Ltd., Beijing, China) for $1 \mathrm{~h}$ at room temperature, the sections were incubated with rabbit anti-mouse PCNA and caspase-3 polyclonal antibodies (both dilution, 1:1,000; Cell Signaling Technology, Inc.) overnight at $4^{\circ} \mathrm{C}$. Then sections were incubated with enzyme-labeled goat anti-rabbit immunoglobulin $\mathrm{G}(\mathrm{IgG})$ polymer from the immunohistochemistry kit for $1 \mathrm{~h}$ at room temperature. In total, $0.5 \mathrm{ml}$ DAB staining solution A, $0.5 \mathrm{ml}$ DAB staining solution B and $1 \mathrm{ml}$ DAB staining working solution were prepared and gently mixed. The sections were incubated with the mixture at $20-25^{\circ} \mathrm{C}$ for $5 \mathrm{~min}$, and the sections were counterstained with $10 \%$ hematoxylin for $30 \mathrm{sec}$ at room temperature. The stained slides were washed thoroughly in running tap water, dehydrated and mounted with cover slips. Hepatocytes positively stained for PCNA and caspase-3 were examined under a light microscope at a magnification of x200, and ImageJ 1.48v software (National Institutes of Health, Bethesda, MD, USA) was used to analyze the area occupied by the positively stained cells.

Terminal uridine nick-end labeling (TUNEL) assay. The In Situ Cell Death Detection kit (with TMR red as the fluorescence marker) was used to detect TUNEL positive apoptotic cells according to the manufacturer's protocol. Apoptosis was observed under fluorescence microscope at a magnification of 
Table I. Suzuki scores for liver ischemia/reperfusion injury.

\begin{tabular}{llll}
\hline Numerical assessment & \multicolumn{1}{c}{ Congestion } & Vacuolization & Necrosis \\
\hline 0 & None & None & None \\
1 & Minimal (10\%) & Minimal (10\%) & Single-cell necrosis \\
2 & Mild (11-30\%) & Mild (11-30\%) & Mild (<30\%) \\
3 & Moderate (31-60\%) & Moderate (31-60\%) & Moderate (31-60\%) \\
\hline
\end{tabular}

x200. The area occupied by the positive cells was analyzed using Image J $1.48 \mathrm{v}$ software.

Cell culture and transfection. AML12 cells were plated at a density of $2 \times 10^{5}$ cells $/ \mathrm{ml}$ in 6 -well plates and divided into 4 treatment groups, as followings: i) A control untreated group; ii) an ischemia/reperfusion (IR) group subjected to hypoxia for $1 \mathrm{~h}$ to simulate ischemia and then cultured in DMEM/F12 for $12 \mathrm{~h}$ to simulate reperfusion; iii) an miR-101 mimetics group transfected with $50 \mathrm{nM}$ miR-101 mimetics or miR-NC using RiboFECTTM for $48 \mathrm{~h}$ at $37^{\circ} \mathrm{C}$, and subjected to hypoxia/reperfusion $48 \mathrm{~h}$ later; and iv) miR-101 inhibitor group transfected with $50 \mathrm{nM}$ miR-101 inhibitor or miR-NC, and subjected to hypoxia/reperfusion $48 \mathrm{~h}$ later. To induce hypoxia, the culture medium was removed $48 \mathrm{~h}$ after transfection and replaced with $2 \mathrm{ml} \mathrm{Hank}$ 's solution (Thermo Fisher Scientific, Inc.), and the cells were placed in a low oxygen incubator. After $1.5 \mathrm{~h}$, Hank's solution was removed and replaced with $2 \mathrm{ml} \mathrm{DMEM} / \mathrm{F} 12$ medium, and the cells were cultured under normal oxygen tension (with $5 \% \mathrm{CO}_{2}$ ) for $12 \mathrm{~h}$ to simulate the reperfused (re-oxygenated) state.

Confocal fluorescence microscopy. AML12 cells were plated in 24-well plates, and cultured until they reached $60-70 \%$ confluence. The cells were transduced with the GFP-RFP-LC3 adenovirus $\left(3 \times 10^{7} \mathrm{PFU} /\right.$ well) for $48 \mathrm{~h}$ at $37^{\circ} \mathrm{C}$ according to the manufacturer's protocol to induce autophagy and the resulting autophagosomes were observed under a confocal microscope at a magnification of $x 1,000$. The number of autophagosomes in each cell was counted, and the mean number of autophagosomes of all cells was calculated to determine the autophagic degree of each treatment group.

$R T-q P C R$. Total RNA was extracted from tissues or cells using TRIzol total RNA isolation reagent (Invitrogen; Thermo Fisher Scientific, Inc.) according to the manufacturer's protocol. Subsequently, the PrimeScript RT reagent kit (Beijing Transgen Biotech Co., Ltd.) was used for RT of the RNA into cDNA, according to the manufacturer's protocol. SYBR-Green RT-qPCR Master Mix was used as the flurophore. RT-qPCR was performed using specific primers for miR-101 (forward, 5'-GTACAGTACTGTGATAACTGA-3' and reverse, 5'-TGC GTGTCGTGGAGTC-3'), mTOR (forward, 5'-TCGGTGCAA ACCTACAGAAGC-3' and reverse, 5'-TGCAGGTCGTAT ATGGACAGAG-3') and GAPDH (forward, 5'-GGAGCG AGATCCCTCCAAAAT-3' and reverse, 5'-GGCTGTTGT CATACTTCTCATGG-3') used as the internal control. The thermocycling conditions were as follows: Pre-denaturation at $94^{\circ} \mathrm{C}$ for $30 \mathrm{sec}$, followed by 45 cycles of denaturation at $94^{\circ} \mathrm{C}$ for $5 \mathrm{sec}$, annealing at $60^{\circ} \mathrm{C}$ for $15 \mathrm{sec}$ and extension at $72^{\circ} \mathrm{C}$ for $10 \mathrm{sec}$. Each sample was tested in quadruplicates. The relative expression of each gene was quantified using the comparative quantification cycle method as follows: Copy number of target gene $=2^{-\Delta \Delta \mathrm{Cq}}, \Delta \mathrm{Cq}=\mathrm{Cq}_{\text {target gene }}-\mathrm{Cq}_{\text {reference gene }}$, $\Delta \Delta \mathrm{Cq}=\Delta \mathrm{Cq}_{\text {experimental group }}-\Delta \mathrm{Cq}_{\text {control group }}(23)$.

Immunofluorescence. AML12 cells were transfected with miR-101 mimetics or miR-101 inhibitors using RiboFECTTM for $48 \mathrm{~h}$ at $37^{\circ} \mathrm{C}$, according to the reagent manufacturer's protocol. Following differentiation and treatments, cells were fixed with $4 \%$ paraformaldehyde for $15 \mathrm{~min}$ at room temperature and permeabilized with $0.1 \%$ Triton $\mathrm{X}-100$ for $5 \mathrm{~min}$ at room temperature. Cells were then incubated for $60 \mathrm{~min}$ at room temperature with blocking solution (5\% goat serum) followed by overnight incubation at $4{ }^{\circ} \mathrm{C}$ with anti-p62 antibodies (dilution, 1:800) Following washing with PBS, cells were incubated with fluorescence-labeled secondary antibodies (Alexa Fluor ${ }^{\circledR}$ 594-conjugated goat polyclonal anti-rabbit; 1:500; cat. no. 8889; Cell Signaling Technology, Inc.) for $1 \mathrm{~h}$ at room temperature in the dark. In addition, DAPI (1:1,000; cat. no. D9564; Sigma-Aldrich; Merck KGaA) was used to non-specifically stain the nuclei and samples were incubated with $50 \mu \mathrm{l}$ DAPI for $10 \mathrm{~min}$ at room temperature. Immunostaining was visualized under a fluorescence microscope at a magnification of $\mathrm{x} 400$.

MTT bioassay. AML12 cells were seeded into 96-well plates $\left(5 \times 10^{4}\right.$ cells/well) and after $24 \mathrm{~h}$ culturing, were treated with Rapa or 3-MA for $2 \mathrm{~h}$, or miR-101 inhibitor for $48 \mathrm{~h}$ at $37^{\circ} \mathrm{C}$ prior to reperfusion. Fresh medium was then added to each well along with $20 \mu \mathrm{l}$ MTT solution $(5 \mathrm{mg} / \mathrm{ml})$, and the cells were incubated for another $4 \mathrm{~h}$ at $37^{\circ} \mathrm{C}$. The medium was then removed, and $200 \mu \mathrm{l}$ dimethylsulfoxide was added per well to stop the reaction. The optical density of each well was determined at $490 \mathrm{~nm}$.

Western blot analysis. Radioimmunoprecipitation assay lysis buffer (Beyotime Institute of Biotechnology, Shanghai, China) were used to extract the total protein from AML12 cells and liver tissues. The protein concentration was determined by Bicinchoninic Acid Protein Assay kit (Solarbio Science $\&$ Technology Co., Ltd.). Equal samples of protein $(30 \mu \mathrm{g})$ were separated by SDS-PAGE on $12 \%$ gels and transferred onto a polyvinylidene difluoride membrane. The membrane was blocked with $5 \%$ skim milk for $1 \mathrm{~h}$ at room temperature. The membrane was then incubated with mTOR, p-mTOR, GAPDH, LC3 II, caspase-3 and p62 (all 1:1,000) primary antibodies overnight at $4^{\circ} \mathrm{C}$. The membranes were then washed 
A

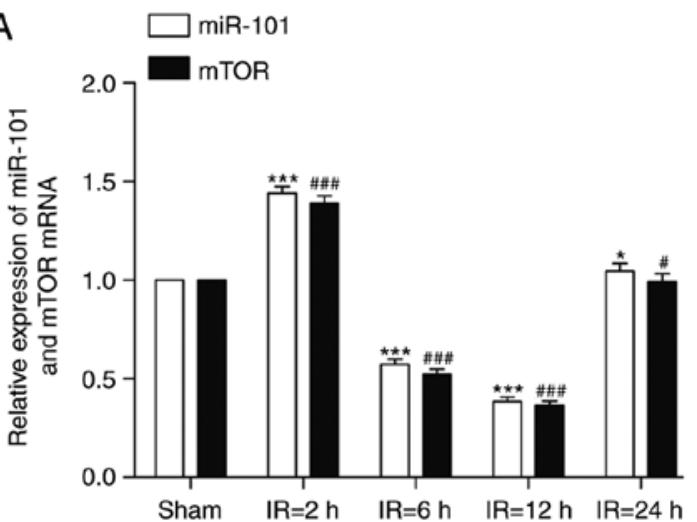

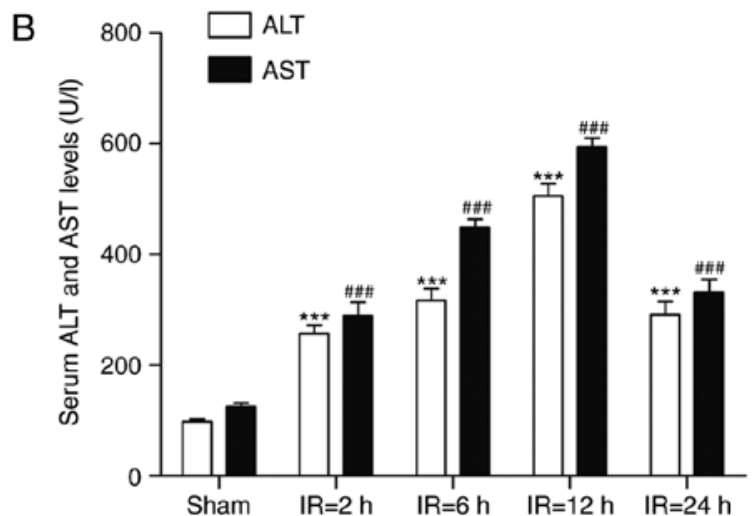
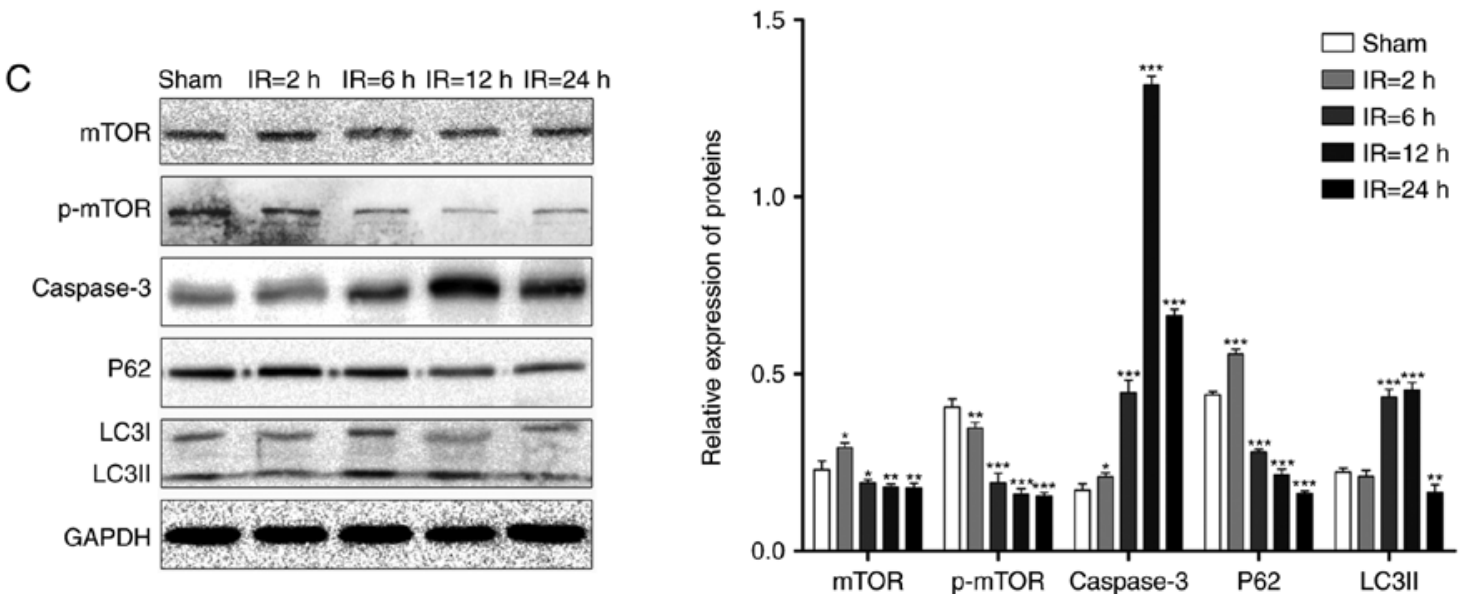

Figure 1. Alterations of miR-101 expression and autophagy signaling in the liver IR injury mouse model. (A) Relative expression levels of miR-101 and mTOR mRNA in mouse liver at each reperfusion time point were detected using reverse transcription-quantitative polymerase chain reaction. ${ }^{*} \mathrm{P}<0.05$ and ${ }^{* * * *} \mathrm{P}<0.001$ vs. miR-101 sham. ${ }^{\#} \mathrm{P}<0.05$ and ${ }^{\# \# \#} \mathrm{P}<0.001$ vs. mTOR sham. (B) Comparison of serum ALT and AST levels at different time points. ${ }^{* * *} \mathrm{P}<0.001$ vs. ALT sham. ${ }^{\# \#} \mathrm{P}<0.001$ vs. AST sham. (C) Western blots exhibiting the levels of mTOR, p-mTOR, caspase-3, p62 and LC3II proteins in the liver at different time points post-reperfusion. GAPDH was used as the internal control. ${ }^{*} \mathrm{P}<0.05,{ }^{* *} \mathrm{P}<0.01$ and ${ }^{* * *} \mathrm{P}<0.001 \mathrm{vs}$. the sham treated group. miR, microRNA; mTOR, mechanistic target of rapamycin; IR, ischemia/reperfusion; ALT, alanine aminotransferase; AST, aspartate aminotransferase; p-, phosphorylated; LC3II, microtubule-associated protein 1 light II.

with TBS-Tween-20 at room temperature (5 $\mathrm{min} /$ wash). Subsequently, the membrane was treated with HRP-conjugated goat anti-rabbit and anti-mouse IgG secondary antibodies (both 1:2,500), agitated and incubated at room temperature for $1 \mathrm{~h}$. The protein bands were visualized by using a G:BOX imaging system (Gene Company, Ltd., Hong Kong, China). The protein bands were measured with ImageJ $1.48 \mathrm{v}$ software and normalized to the corresponding GAPDH bands. The relative density of each target protein normalized to the control was used to represent the changes in expression of target proteins.

Statistical analysis. Statistical analysis was performed using SPSS 22.0 software (IBM Corp., Armonk, NY, USA). Normally distributed data were expressed as the mean \pm standard deviation $(\mathrm{x} \pm \mathrm{s})$. A Student's $\mathrm{t}$ test was used for comparing two groups, a one-way analysis of variance for comparing multiple groups and the Least-Significant-Difference method was used as a post-hoc test for multiple comparisons between groups. $\mathrm{P}<0.05$ was considered to indicate a statistically significant difference.

\section{Results}

LIRI alters the expression of miR-101 and mTOR in mouse liver. The expression levels of miR-101 and mTOR mRNA initially significantly increased following reperfusion compared with their respective sham groups $(\mathrm{P}<0.001)$, but significantly decreased in the liver of the IR mouse model following reperfusion at 6 and $12 \mathrm{~h}$ compared with the respective sham groups $(\mathrm{P}<0.001 ;$ Fig. 1A).

LIRI alters serum AST and ALT levels. The levels of serum AST and ALT were significantly increased following reperfusion in a time-dependent manner compared with the sham groups $(\mathrm{P}<0.001)$. Compared with the sham-treated group, the IR mice exhibited a gradual increase in the serum AST and ALT levels that peaked at $12 \mathrm{~h}(\mathrm{P}<0.001$; Fig. 1B).

LIRI affects apoptosis and autophagy. As presented in Fig. 1C, LC3II expression levels significantly increased following 6 and $12 \mathrm{~h}$ reperfusion and peaked at $12 \mathrm{~h}$ compared with the sham group $(\mathrm{P}<0.01)$ and the pro-apoptotic caspase-3 was also significantly upregulated following reperfusion with maximum expression at $12 \mathrm{~h}$ post-reperfusion compared with the sham group $(\mathrm{P}<0.05)$. Although the expression levels of mTOR and p62 increased after $2 \mathrm{~h}$ reperfusion, the expression levels of mTOR, p-mTOR and p62 significantly decreased steadily in a time-dependent manner following reperfusion at 6,12 and $24 \mathrm{~h}(\mathrm{P}<0.05)$. 
A
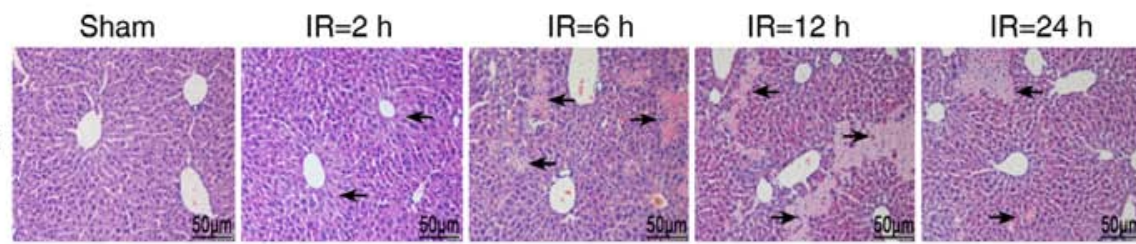

B

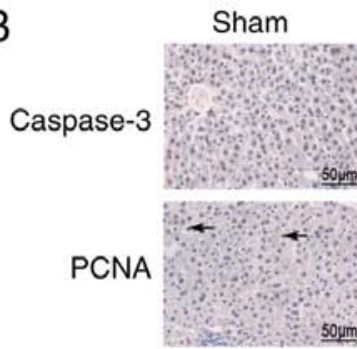

$\mathrm{IR}=2 \mathrm{~h}$

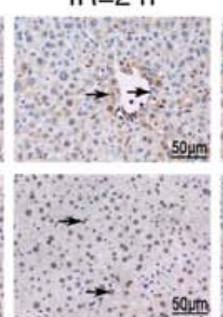

$\mathrm{IR}=6 \mathrm{~h}$

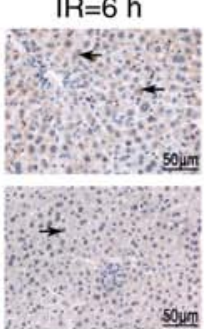

$\mathrm{IR}=12 \mathrm{~h}$

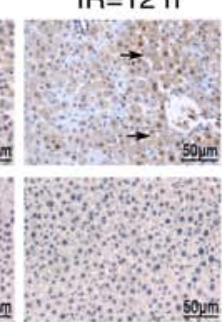

$\mathrm{IR}=24 \mathrm{~h}$
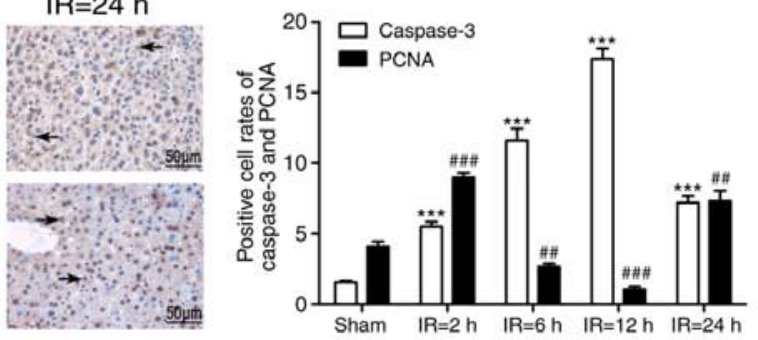

Sham $\quad \mathbb{R}=2 \mathrm{~h} \quad \mathbb{I R}=6 \mathrm{~h} \quad \mathbb{I R}=12 \mathrm{~h} \quad \mathbb{I R}=24 \mathrm{~h}$
C
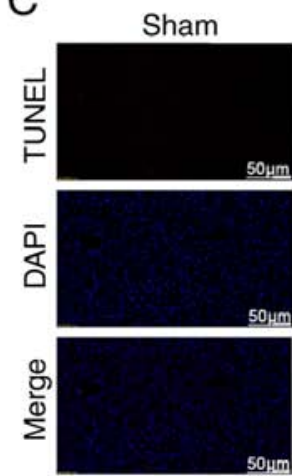

$\mathrm{IR}=2 \mathrm{~h}$
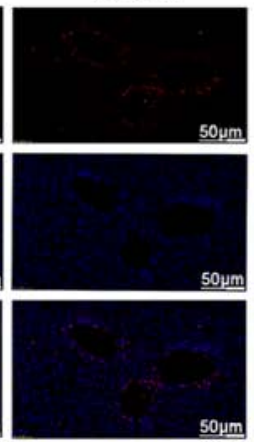

$\mathrm{IR}=6 \mathrm{~h}$
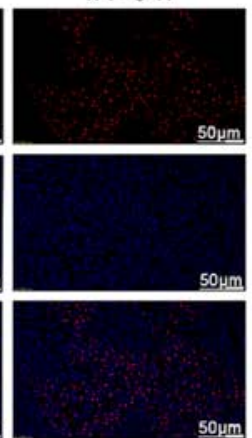

$\mathrm{IR}=12 \mathrm{~h}$
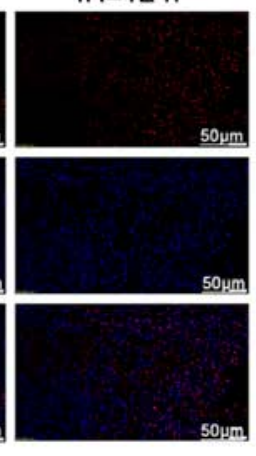
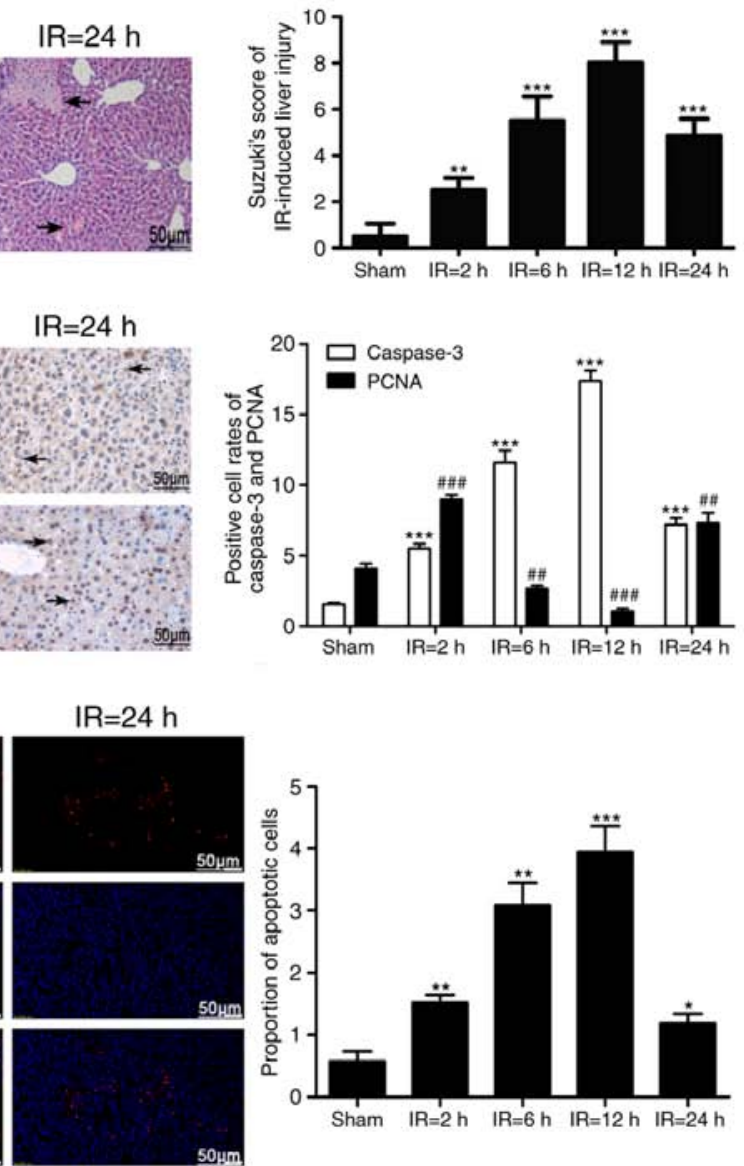

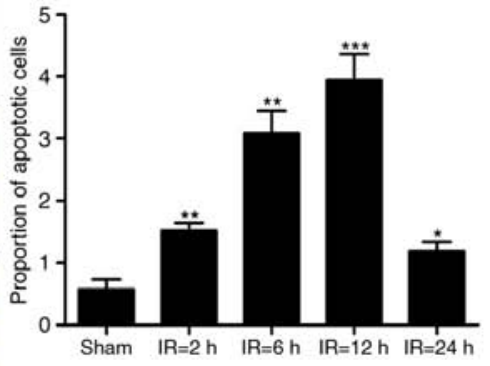

Figure 2. Histopathological changes during liver IR injury. (A) Representative images of H\&E-stained liver sections presenting characteristic histopathological changes associated with IR (x200 magnification; left panel), black arrows indicate hepatocyte edema, apoptosis and necrosis observed after 6 and $12 \mathrm{~h}$ reperfusion. Scale bars $=50 \mu \mathrm{m}$. Column graph comparing the Suzuki's score of IR-induced liver injury in all groups (right). ${ }^{* *} \mathrm{P}<0.01$ and ${ }^{* * *} \mathrm{P}<0.001$ vs. the sham-treated group. (B) Representative immunohistochemistry images revealing the expression of caspase-3 and PCNA (x200 magnification; scale bars $=50 \mu \mathrm{m}$; left panel). Column graph comparing the percentage of caspase- 3 and PCNA positive cells in different groups (right). ${ }^{* * *} \mathrm{P}<0.001 \mathrm{vs}$. caspase-3 sham. ${ }^{\# \#} \mathrm{P}<0.01$ and ${ }^{\# \#} \mathrm{P}<0.001$ vs. PCNA sham. (C) Representative images presenting TUNEL-positive apoptotic nuclei (red) with DAPI counterstaining (x200 magnification; scale bars $=50 \mu \mathrm{m}$; left panel). Column graph comparing the percentage of TUNEL-positive cells in the liver analyzed using Image $\mathrm{J}$ software (right). ${ }^{*} \mathrm{P}<0.05,{ }^{* *} \mathrm{P}<0.01$ and ${ }^{* * *} \mathrm{P}<0.001$ vs. the sham-treated group. IR, ischemia/reperfusion; H\&E, haemotoxylin and eosin; PCNA, proliferating cell nuclear antigen; TUNEL, terminal uridine nick-end labeling; DAPI, 3,3'-diaminobenzidine.

Histopathological changes in the liver following IRI. The liver tissues of the IR mice demonstrated edema, ballooning, steatosis, flaky necrosis, neutrophil infiltration and congestion, in addition to the disappearance of the hepatic sinusoidal structure in certain areas. These lesions were substantially aggravated with time, with the severest injuries observed at $12 \mathrm{~h}$ after reperfusion, but were relieved at $24 \mathrm{~h}$ post-reperfusion. In addition, IR-induced liver damage was quantified by measuring the Suzuki score, which gradually significantly increased following reperfusion compared with the sham group $(\mathrm{P}<0.01$; Fig. 2A).

IRI alters proliferation and apoptosis of liver cells. Compared with the sham-treated group (Fig. 2B), the intra-nuclear expression of the proliferative marker PCNA significantly decreased following reperfusion at the 6 and $12 \mathrm{~h}$ mark, despite initially increasing at the $2 \mathrm{~h}$ mark and again increasing at the $24 \mathrm{~h}$ mark $(\mathrm{P}<0.01)$. The cytoplasmic expression of caspase-3 gradually significantly increased in the liver cells of IR mice with time compared with the sham group $(\mathrm{P}<0.001)$ and a peak change was observed $12 \mathrm{~h}$ after reperfusion. Additionally, as presented in Fig. 2C, the number of TUNEL-positive apoptotic cells were also significantly higher in the IR groups compared with the sham-treated group $(\mathrm{P}<0.05)$. The apoptotic changes were time dependent, with peak alterations observed $12 \mathrm{~h}$ after reperfusion.

miR-101 weakens LIRI by inhibiting apoptosis. As presented in Fig. 3A, the expression levels of mTOR in the miR-101 agomir group were significantly increased compared with the mTOR miR-NC group $(\mathrm{P}<0.001)$, while the expression levels of mTOR in the mir-101 antagomir group were significantly decreased compared with the mTOR miR-NC group ( $\mathrm{P}<0.01$; Fig. 3A). The miR-101 antagomir significantly aggravated the histopathological changes in the liver and the corresponding Suzuki scores induced by IR treatment, while miR-101 agomir significantly alleviated these changes compared with the miR-101 miR-NC group $(\mathrm{P}<0.001$; Fig. 3B). The overexpression of miR-101 significantly reduced the expression of LC3II and caspase-3 compared with the miR-101 miR-NC group $(\mathrm{P}<0.001)$ and significantly increased that of mTOR compared with the miR-101 miR-NC group $(\mathrm{P}<0.01$; Fig. 3C). IR-induced apoptosis was significantly 

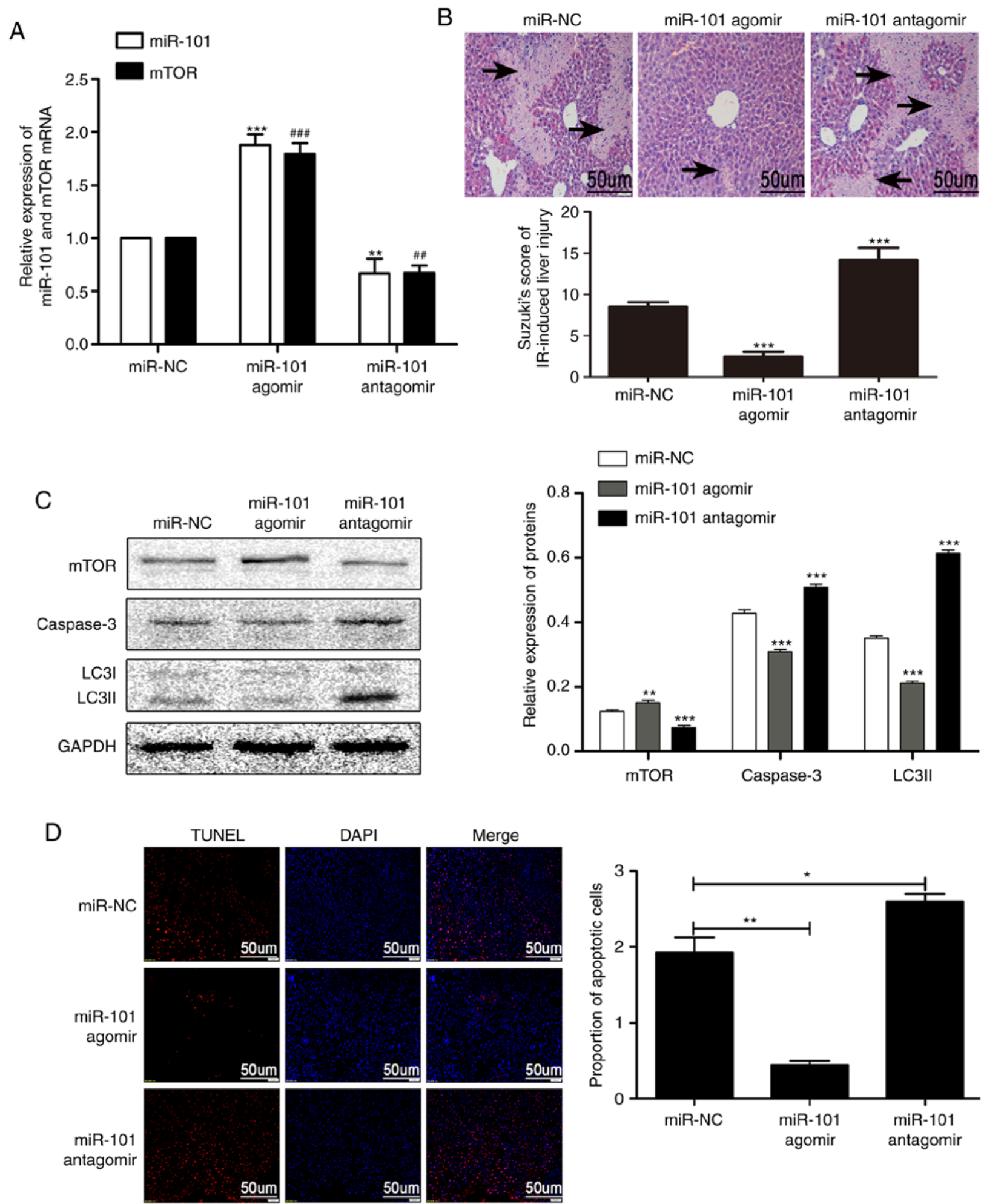

Figure 3. miR-101 ameliorates liver IR injury by inhibiting apoptosis. (A) Relative expression levels of miR-101 and mTOR mRNA in response to miR-101 agomir/antagomir were detected using reverse transcription-quantitative polymerase chain reaction. ${ }^{* * *} \mathrm{P}<0.01$ and ${ }^{* * * *} \mathrm{P}<0.001$ vs. miR-101 miR-NC group. ${ }^{\# \#} \mathrm{P}<0.01$ and ${ }^{\# \# \#} \mathrm{P}<0.001$ vs. mTOR miR-NC group. (B) Representative images of haemotoxylin and eosin-stained liver sections presenting histopathological changes (x200 magnification; scale bars $=50 \mu \mathrm{m}$ ) following miR-101 agomir or antagomir injection. ${ }^{* * *} \mathrm{P}<0.001 \mathrm{vs}$. miR-NC group. (C) Western blots presenting mTOR, caspase- 3 and LC3II levels in the liver. ${ }^{* *} \mathrm{P}<0.01$ and ${ }^{* * * * *} \mathrm{P}<0.001$ vs. the miR-NC group. (D) Representative images of TUNEL stained apoptotic nuclei (red) with DAPI counterstaining (x200 magnification; scale bars $=50 \mu \mathrm{m}$ ), and comparison of the percentage of apoptotic cells analyzed using Image J software. ${ }^{*} \mathrm{P}<0.05$ and ${ }^{* *} \mathrm{P}<0.01$ with comparisons shown by lines. miR, microRNA; mTOR, mechanistic target of rapamycin; NC, negative control; IR, ischemia/reperfusion; LC3II, microtubule-associated protein 1 light II; TUNEL, terminal uridine nick-end labeling; DAPI, 3,3'-diaminobenzidine.

increased by miR-101 antagomir compared with the miR-NC group $(\mathrm{P}<0.05)$ and alleviated by miR-101 agomir compared with the miR-NC group ( $\mathrm{P}<0.01$; Fig. 3D).
Inhibition of autophagy enhances the protective effect of miR-101 on LIRI. Treatment of the IR mice with the autophagy inhibitor 3-MA in addition to miR-101 transfection signifi- 

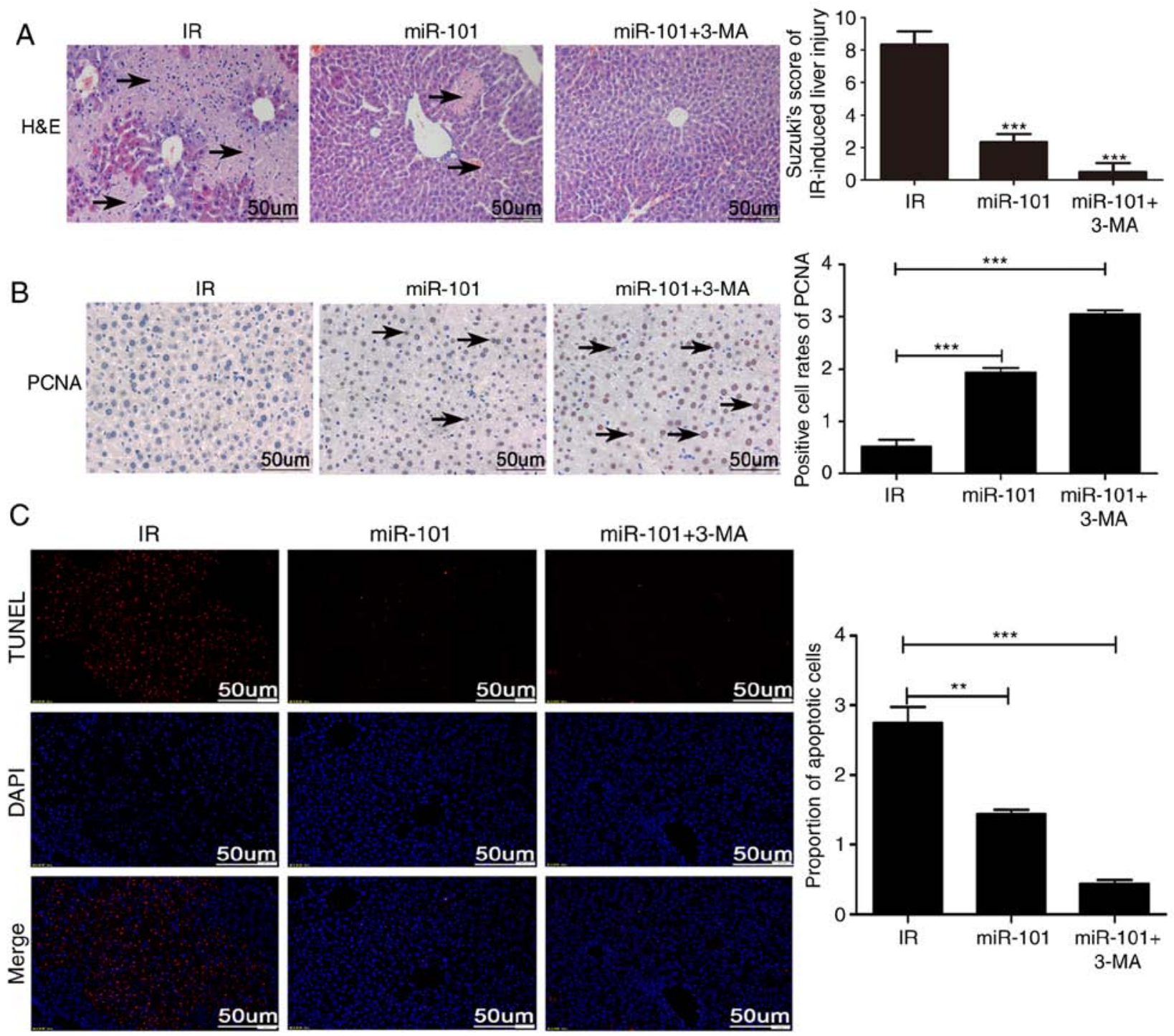

$\mathrm{D}$
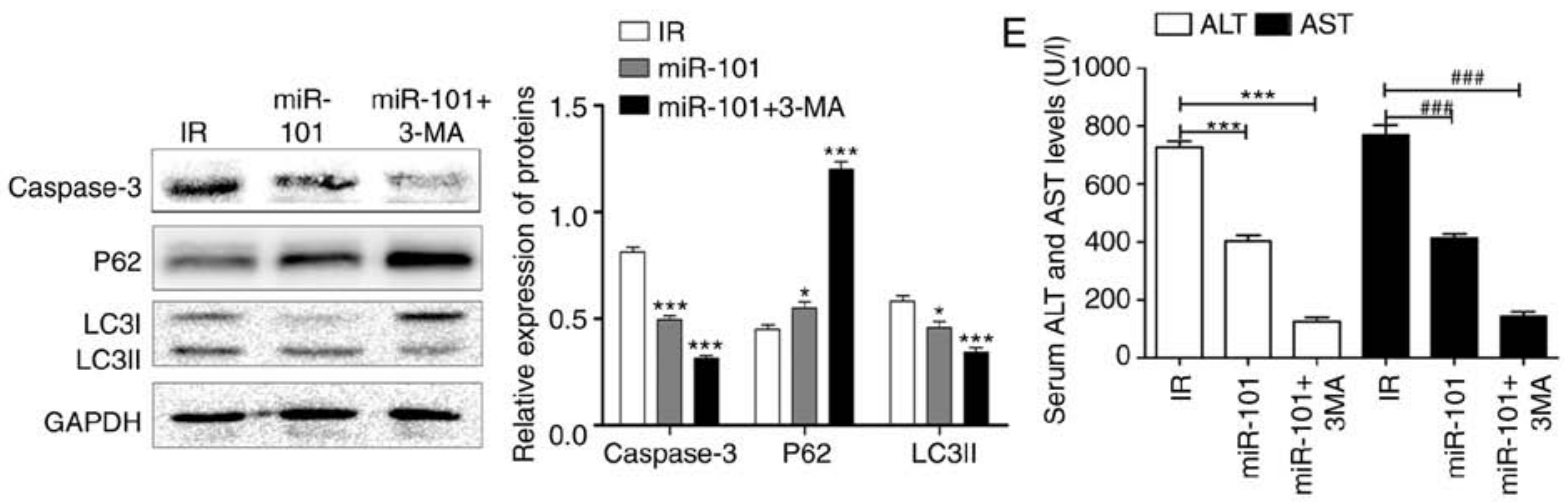

Figure 4. Inhibition of autophagy enhances the protective effect of miR-101 on liver IR injury. (A) Histopathological changes in liver tissue subsequent to treatment with autophagy inhibitor (3-MA; x 200 magnification). Scale bars $=50 \mu \mathrm{m}$. ${ }^{* * *} \mathrm{P}<0.001 \mathrm{vs}$. IR group. (B) Representative immunohistochemistry images of liver tissues presenting nuclear staining of PCNA (x200 magnification; scale bars $=50 \mu \mathrm{m}$ ), and comparisons of the percentage of PCNA-stained cells in different groups. ${ }^{* * *} \mathrm{P}<0.001$ with comparisons shown by lines. (C) Representative images of TUNEL stained (red nuclei) apoptotic cells with DAPI counterstaining (x200 magnification; scale bars $=50 \mu \mathrm{m}$ ), and the percentage of TUNEL positive cells analyzed using Image $\mathrm{J}$ software. ${ }^{* *} \mathrm{P}<0.01$ and ${ }^{* * * *} \mathrm{P}<0.001 \mathrm{with}$ comparisons shown by lines. (D) Western blots presenting LC3II, p62 and caspase-3 protein levels. ${ }^{*} \mathrm{P}<0.05$ and ${ }^{* * * *} \mathrm{P}<0.001$ vs. the IR group. (E) Comparison of serum ALT and AST in different groups. ${ }^{* * * *} \mathrm{P}<0.001$ with comparisons shown by lines. ${ }^{\# \# \#} \mathrm{P}<0.001$ with comparisons shown by lines. miR, microRNA; IR, ischemia/reperfusion; 3-MA, 3-methyladenine; PCNA, proliferating cell nuclear antigen; H\&E, haemotoxylin and eosin; TUNEL, terminal uridine nick-end labeling; DAPI, 3,3'-diaminobenzidine; LC3II, microtubule-associated protein 1 light II; ALT, alanine aminotransferase; AST, aspartate aminotransferase.

cantly reduced the IR-induced histopathological changes and Suzuki scores compared with the IR group $(\mathrm{P}<0.001$; Fig. 4A) and significantly increased the nuclear expression of PCNA compared with the untreated IR group $(\mathrm{P}<0.001$; Fig. 4B). In addition, IR-induced apoptosis was significantly reduced in the mice treated with miR-101+3-MA compared with the 

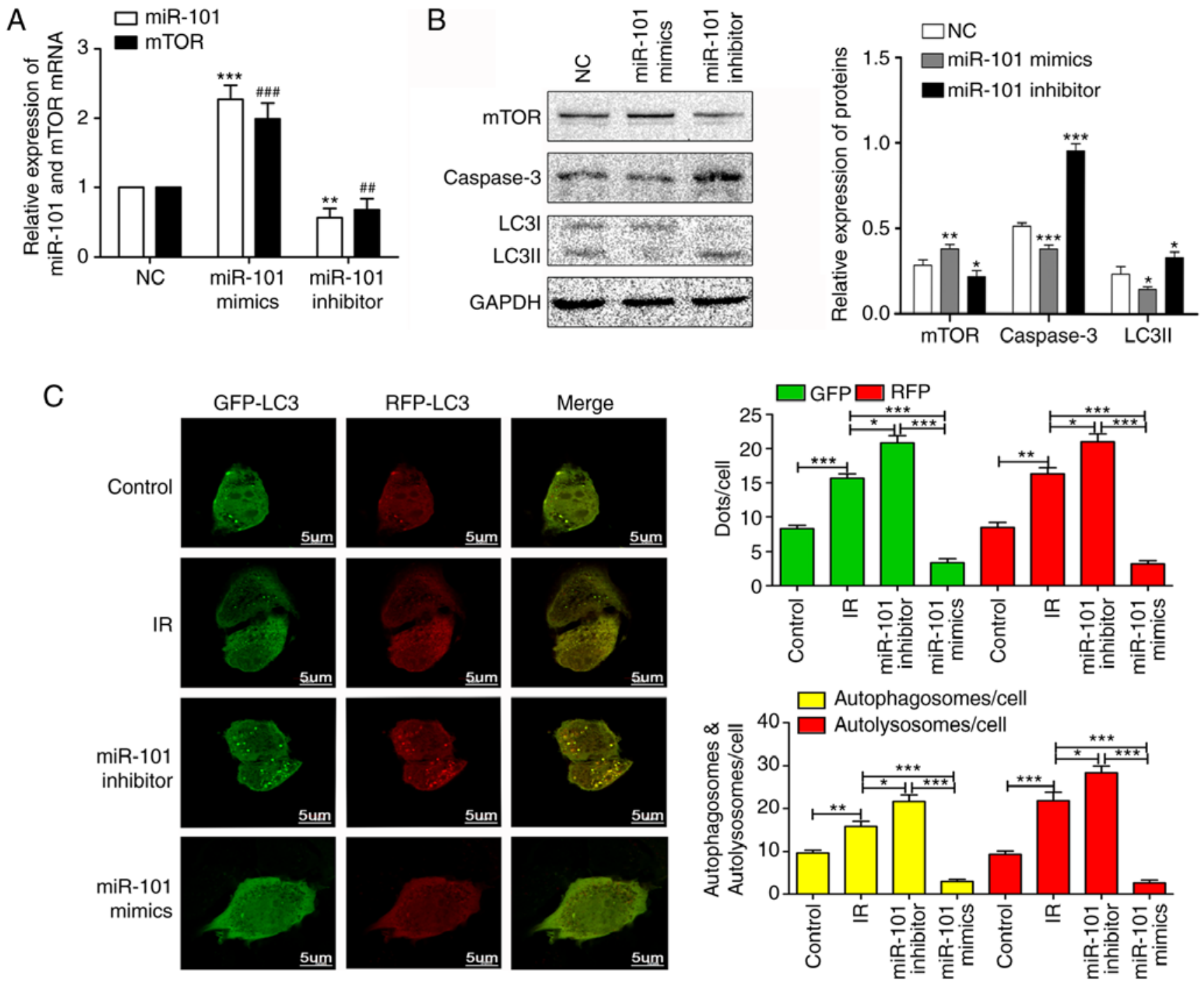

D
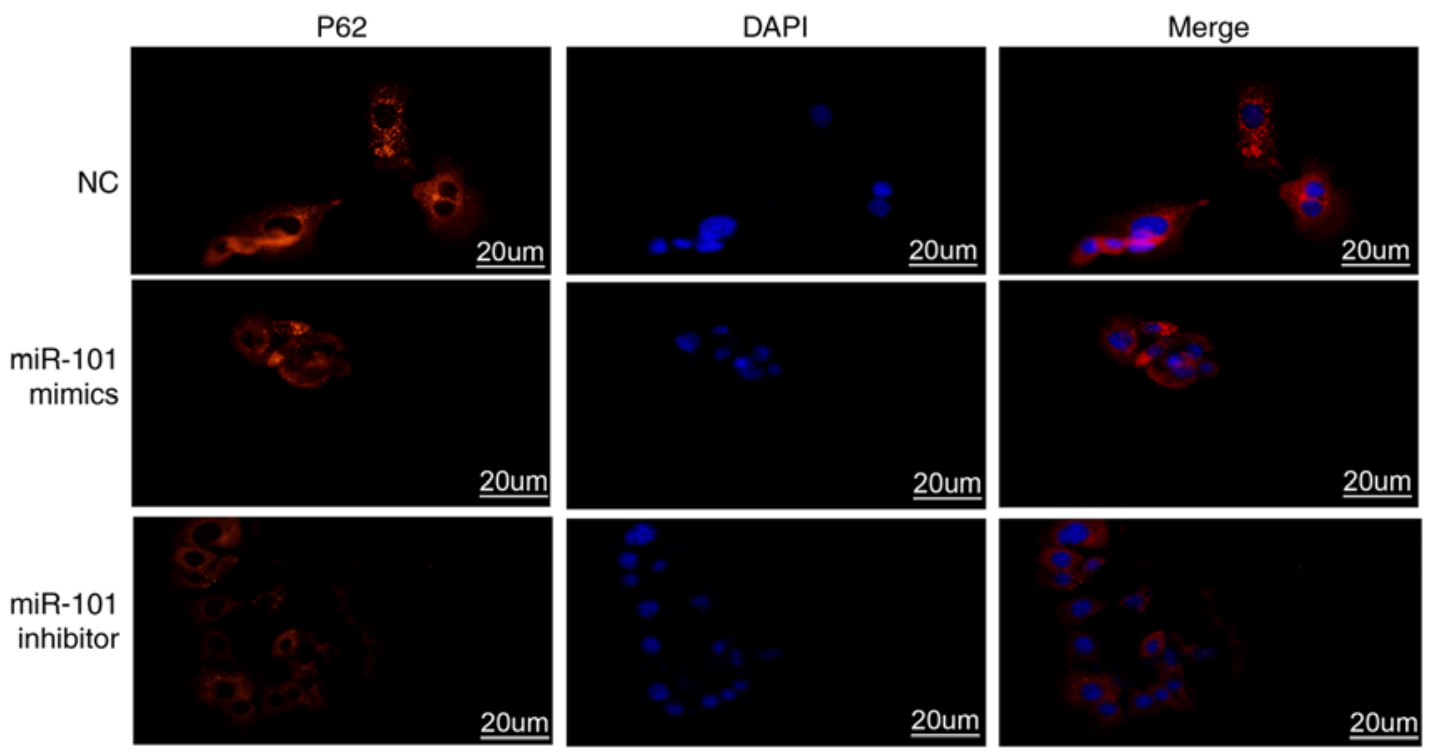

Figure 5. miR-101 inhibits autophagy and weakens IR injury by activating the mTOR pathway in vitro. (A) Relative expression levels of miR-101 and mTOR mRNA in response to miR-101 mimetics/inhibitors. ${ }^{* *} \mathrm{P}<0.01$ and ${ }^{* * *} \mathrm{P}<0.001$ vs. the miR-101 NC group. ${ }^{\# \#} \mathrm{P}<0.01$ and ${ }^{\# \# \#} \mathrm{P}<0.001$ vs. the mTOR NC group. (B) Western blots presenting mTOR, caspase-3 and LC3II levels in AML12 cells. ${ }^{*} \mathrm{P}<0.05,{ }^{* * *} \mathrm{P}<0.01$ and ${ }^{* * * *} \mathrm{P}<0.001$ vs. NC group. (C) Representative confocal images of immunofluorescent GFP-RFP-LC3 expression in AML12 cells. Yellow dots indicate the autophagosomes with GFP and RFP merging, and the red dots represent the autolysosomes with degraded GFP due to the acidic environment. Scale bars $=5 \mu \mathrm{m}$. $\mathrm{P}<0.05,{ }^{* *} \mathrm{P}<0.01$ and ${ }^{* * * *} \mathrm{P}<0.001$ with comparisons shown by lines. (D) Representative immunofluorescence images presenting the expression of p62 in AML12 at x400 magnification. Scale bars=20 $\mu \mathrm{m}$. miR, microRNA; mTOR, mechanistic target of rapamycin; NC, negative control; LC3II, microtubule-associated protein 1 light II; IR, ischemia/reperfusion; GFP, green fluorescence protein; RFP, red fluorescence protein; DAPI, 3,3'-diaminobenzidine. 
A

$\begin{array}{rrrr}\text { IR } & + & + & + \\ \text { Rapa } & - & + & + \\ \text { miR-101 inhibitor } & - & - & +\end{array}$
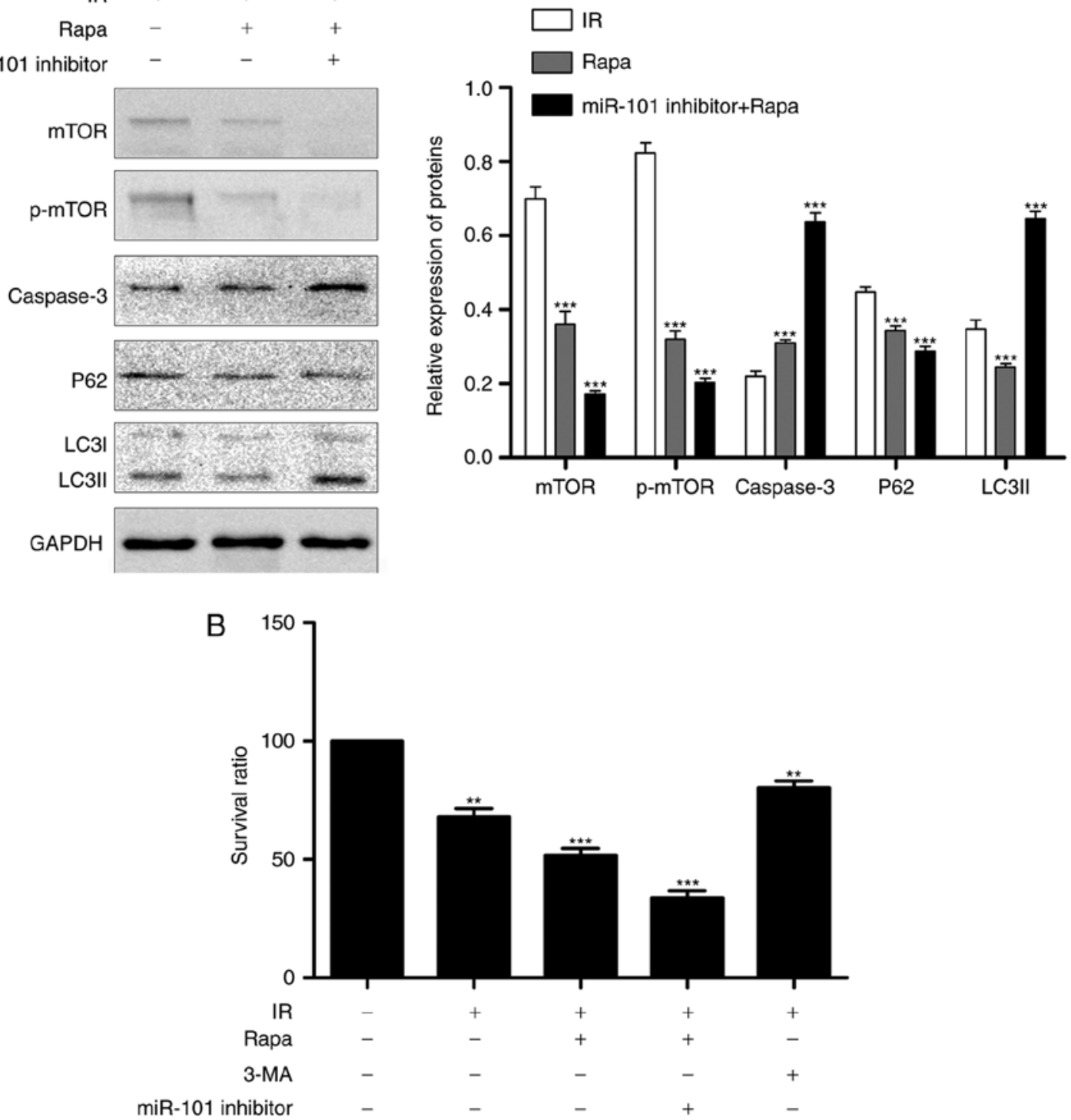

Figure 6. Inhibition of miR-101 and mTOR expression aggravates liver IR injury. (A) Western blots presenting mTOR, p-mTOR, caspase-3, p62 and LC3II levels in AML12 cells. (B) Column graph presenting the percentage of surviving cells in each treatment group. ${ }^{* *} \mathrm{P}<0.01$ and ${ }^{* * * *} \mathrm{P}<0.001$ vs. the IR group. miR, microRNA; mTOR, mechanistic target of rapamycin; IR, ischemia/reperfusion; p-, phosphorylated; LC3II, microtubule-associated protein 1 light II; Rapa, rapamycin.

untreated IR group $(\mathrm{P}<0.001 ;$ Fig. 4C) and validated by the significantly lower expression levels of caspase-3 and LC3II and the upregulation in p62 levels compared with the IR group $(\mathrm{P}<0.001$; Fig. 4D). Serum AST and ALT levels were also significantly lower in the miR-101+3-MA group compared with the IR group $(\mathrm{P}<0.001$; Fig. 4E).

miR-101 inhibits autophagy and weakens LIRI by activating the mTOR pathway in vitro. As presented in Fig. 5, the expression levels of mTOR in the miR-101 mimetics group were significantly increased compared with the mTOR NC group $(\mathrm{P}<0.001)$, while the expression level of mTOR in the miR-101 inhibitor group was significantly decreased compared with the mTOR NC group ( $\mathrm{P}<0.01$; Fig. 5A). In addition, the overexpression of miR-101 significantly reduced the expression of LC3II and caspase- 3 compared with the $\mathrm{NC}$ group $(\mathrm{P}<0.05$; Fig. 5B). The Ad-GFP-RFP-LC3 system was used to determine the potential function of miR-101 in modulating autophagy subsequent to simulated-IR in AML12 cells. The presence of co-localized
GFP-LC3 or RFP-LC3 granules indicate the recruitment of the LC3 protein to autophagosomes, which are formed when autophagy is triggered (24). When autophagosomes fuse with lysosomes and form autolysosomes, GFP but not RFP degrades in the acidic environment, resulting in solely red granules (25). As presented in Fig. 5C, the number of autophagosomes in the miR-101 mimetics group was significantly lower compared with that in the IR group $(\mathrm{P}<0.001)$, indicating that miR-101 inhibits autophagy. Furthermore, the number of autophagosomes significantly increased upon miR-101 inhibition compared with that in the IR group $(\mathrm{P}<0.05)$. In addition, p62 was upregulated in the miR-101 mimetics group and was downregulated in the miR-101 inhibitor group compared with the NC group (Fig. 5D). Altogether, the overexpression of miR-101 inhibited the formation of autophagosomes and autolysosomes, and thus attenuated autophagy.

Inhibition of miR-101 and mTOR expression aggravates LIRI. Reperfusion was established following the pre-treatment of 
AML12 cells with miR-101 inhibitor and mTOR inhibitor rapamycin. The expression of LC3II and caspase-3 were significantly increased compared with the IR group $(\mathrm{P}<0.001$; Fig. 6A), and the percentage of viable cells was significantly decreased following co-suppression compared with the IR group $(\mathrm{P}<0.001$; Fig. 6B).

\section{Discussion}

Liver transplantation is the only treatment option currently available for end-stage liver disease. Unfortunately, it is associated with various complications, including LIRI, which is a common pathophysiological consequence of liver surgery (26). The mechanism of LIRI is complex, and is closely associated with inflammation, metabolic disorders, oxidative stress and autophagy. In addition, each of these factors may be mutually antagonistic or synergistic (27).

Autophagy is an intracellular self-digestion pathway present in the majority of eukaryotic cells, which helps in organelle recycling and fulfils cellular metabolic requirements under stress conditions (28). The autophagy-related genes (Atgs) induce the detachment of bilayer membrane structures from the rough endoplasmic reticulum, which then encapsulate organelles and other cytoplasmic contents to form autophagosomes. The latter then fuse with lysosomes to form autolysosomes, and the intra-vesicular contents are degraded by the lysosomal enzymes (29). LC3/Atg8 is a marker of the autophagosome membrane, and the conversion of LC3I to LC3II is used as a measure of autophagosome formation (30). One previous study has demonstrated that hepatic autophagy is notably enhanced in LIRI models (31), but the underlying mechanism is not fully understood. Autophagy functions as a double-edged sword in hepatic IR and influences cell survival and apoptosis (32). In moderate IRI, the autophagosomes digest damaged organelles and provide energy to the cells. However, severe reperfusion injury results in excessive autophagy, which may trigger cell death (33). Therefore, targeting the autophagy pathway may effectively protect against IRI (34).

In previous years, studies have focused on the function of miRNAs in hepatic IRI, particularly their involvement in autophagy (35-37). miRNAs are able to regulate autophagy by inhibiting the expression of target genes, which in turn affect IRI (13). Previous studies have demonstrated that miR-17 upregulated autophagy and aggravated the degree of LIRI by inhibiting Stat3 expression in LIRI (31), while miR-30b reduced autophagy and protected against LIRI by inhibiting Atg12-Atg5 binding (38). Studies have additionally demonstrated that the inhibition of miR-34a enhanced sirtuin 1 expression, which downregulated autophagy and subsequently protected the liver from p65/p53 deacetylation-induced damage $(39,40)$. Therefore, the miRNAs regulating autophagy in LIRI may be potential therapeutic targets. miRNAs typically function by causing mRNA degradation through interacting with the 3'-UTR of the target mRNAs, resulting in mRNA degradation and/or translational repression (12). Conversely, the miRNA-mediated upregulation of target mRNAs may be elucidated by direct activation and/or indirect derepression to enhance mRNA stability and translational activation (41). Studies have demonstrated that in miRNA-mediated upregulation, micro-ribonucleoprotein (miRNP) trans-expression promotes the expression of its target mRNA, which is similar to miRNA-mediated downregulation (42-44). MRNA expression may be activated directly by miRNP and/or alleviated indirectly from miRNA-mediated inhibition by eliminating the inhibitory effect of miRNP (45).

The present study investigated whether miR-101 was able to affect autophagy and serve a function in LIRI through the mTOR pathway. In previous studies, miR-101 was able to inhibit tumor growth by inhibiting autophagy (46-48). mTOR is a notable serine-threonine protein kinase downstream of phosphoinositide-3-kinase (PI3K)/protein kinase B (Akt) (49) and inhibits autophagy during tumor growth and progression $(17,47)$. Li et al $(50)$ revealed that octreotide is able to upregulate the expression of miR-101 and inhibit autophagy by inactivating AMP-activated protein kinase (AMPK) and activating the mTOR pathway, thereby reducing the incidence of intestinal mucositis following anticancer treatment. However, little is known regarding the function of the miR101/mTOR axis in LIRI.

The present study revealed that IRI induced a number of pathological, functional and molecular changes in the liver, including increased serum levels of ALT and AST, the downregulation of miR-101, mTOR mRNA and p62, increased levels of LC3II and caspase-3, decreased intra-nuclear PCNA and extensive tissue necrosis and apoptosis. PCNA is closely associated with cellular DNA synthesis and therefore a good indicator of cell proliferation status $(51,52)$. Caspase- 3 is a necessary terminal cleavage enzyme in the intrinsic apoptotic pathway, and an established indicator of apoptosis (53).

Based on the results of the present study, miR-101 was negatively associated with autophagy. Furthermore, the overexpression of miR-101 reduced apoptosis, increased mTOR expression and decreased LC3II and caspase-3 levels, whilst the inhibition of miR-101 had the reverse effects. In addition, the inhibition of autophagy by 3-MA augmented the protective effects of miR-101 overexpression against LIRI.

To assess the hypothesis that miR-101 regulates the mTOR signaling pathway, the present study investigated the function of miR-101 in the regulation of the mTOR signaling pathway. The overexpression of miR-101 in LIRI-mimicking AML12 cells increased mTOR expression, decreased the number of autophagosomes and increased p62 expression. miR-101 inhibition exhibited the reverse effects on mTOR expression and autophagosome formation. Subsequently, miR-101 and mTOR were co-inhibited in AML12 cells, and it resulted in an increase in autophagy and cell death. These results indicate that miR-101 protects hepatocytes against IR injury by inhibiting autophagy via activation of mTOR signaling pathway.

The present study identified the inhibitory effect of miR-101 on autophagy in LIRI by regulating the expression of mTOR. But, a number of limitations of the present study should be taken into consideration. For example, the underlying mechanisms of the inductory effect of miR-101 on mTOR should be further studied. However, microRNA regulation is multi-directional. Nikoonahad et al (54) revealed that miR-101 inhibits the growth of AML cancer cells by directly upregulating the expression of the pro-apoptotic gene $\mathrm{Bcl} 2$ 
like11 (BIM). Different diseases and different conditions may cause miRNAs to exhibit distinct regulatory mechanisms. In addition, as one of the substrates of Akt, the P13K/Akt/mTOR regulatory pathway has been confirmed to serve a necessary function in cell growth and regulation (55). At present, the function of miR-101 in LIRI through the P13K/Akt/mTOR regulatory pathway remains to be further verified. AMPK is a cellular energy receptor, and a number of studies have demonstrated that AMPK is a negative regulator of the mTOR pathway $(56,57)$. Studies have also revealed that miR-101 may inhibit the action of AMPK by directly targeting the 3'-UTR region of AMPK $(58,59)$. Therefore, miR-101 is likely to regulate the mTOR signaling pathway and serve a function in LIRI by affecting the expression of AMPK. Whether miR-101 affects the expression of mTOR by regulating AMPK in LIRI and whether there are other regulatory objectives and mechanisms has yet to be further studied.

In conclusion, the present study revealed that miR-101 attenuates LIRI by activating the mTOR pathway and inhibiting autophagy. Further studies are required to further dissect the association between autophagy and miRNAs in hepatocytes following IR in order to develop novel therapies.

\section{Acknowledgements}

Not applicable.

\section{Funding}

The present study was supported by the Tianjin Clinical Research Center for Organ Transplantation Project (grant no. 15ZXLCSY00070).

\section{Availability of data and materials}

The datasets used and analyzed during the present study are available from the corresponding author on reasonable request.

\section{Authors' contributions}

HS and JZ conceived and designed the experiments. HS, CD and XW performed the experiments. HS, JZ and ZS analyzed the data. HS and CD wrote the paper. All authors read and approved the final manuscript.

\section{Ethics approval and consent to participate}

The use and care of the animal were in accordance with the Guide for the Care and Use of Laboratory Animals published by the US National Institutes of Health (18). The research protocols were approved by the Ethics Committee of Tianjin First Center Hospital (Tianjin, China).

\section{Patient consent for publication}

Not applicable.

\section{Competing interests}

The authors declare that they have no competing interests.

\section{References}

1. Cursio R, Colosetti P and Gugenheim J: Autophagy and liver ischemia-reperfusion injury. Biomed Res Int 2015: 417590, 2015.

2. Rautou PE, Mansouri A, Lebrec D, Durand F, Valla D and Moreau R: Autophagy in liver diseases. J Hepatol 53: 1123-1134, 2010.

3. Sun P, Zhang P, Wang PX, Zhu LH, Du Y, Tian S, Zhu X and Li H: Mindin deficiency protects the liver against ischemia/reperfusion injury. J Hepatol 63: 1198-1211, 2015.

4. Clavien PA: How far can we go with marginal donors? J Hepatol 45: 483-484, 2006.

5. Halazun KJ, Quillin RC, Rosenblatt R, Bongu A, Griesemer AD, Kato T, Smith C, Michelassi F, Guarrera JV, Samstein B, et al: Expanding the margins: High volume utilization of marginal liver grafts among $\geq 2000$ liver transplants at a single institution. Ann Surg 266: 441-449, 2017.

6. Lentsch AB, Kato A, Yoshidome H, McMasters KM and Edwards MJ: Inflammatory mechanisms and therapeutic strategies for warm hepatic ischemia/reperfusion injury. Hepatology 32: 169-173, 2000.

7. Qu Y, Zhang Q, Cai X, Li F, Ma Z, Xu M and Lu L: Exosomes derived from miR-181-5p-modified adipose-derived mesenchymal stem cells prevent liver fibrosis via autophagy activation. J Cell Mol Med 21: 2491-2502, 2017.

8. Tang B, Bao N, He G and Wang J: Long noncoding RNA HOTAIR regulates autophagy via the miR-20b-5p/ATG7 axis in hepatic ischemia/reperfusion injury. Gene 686: 56-62, 2019.

9. Chen J, Yu Y, Li S, Liu Y, Zhou S, Cao S, Yin J and Li G: MicroRNA-30a ameliorates hepatic fibrosis by inhibiting beclin1-mediated autophagy. J Cell Mol Med 21: 3679-3692, 2017.

10. Lim LP, Glasner ME, Yekta S, Burge CB and Bartel DP: Vertebrate microRNA genes. Science 299: 1540, 2003.

11. Weiss JB, Eisenhardt SU, Stark GB, Bode C, Moser M and Grundmann S: MicroRNAs in ischemia-reperfusion injury. Am J Cardiovasc Dis 2: 237-247, 2012.

12. Valinezhad Orang A, Safaralizadeh R and Kazemzadeh-Bavili M: Mechanisms of miRNA-mediated gene regulation from common downregulation to mRNA-specific upregulation. Int J Genomics 2014: 970607, 2014.

13. Yang Y and Liang C: MicroRNAs: An emerging player in autophagy. ScienceOpen Res 2015: 14293/S2199-1006, 2015.

14. Bartel DP: Metazoan MicroRNAs. Cell 173: 20-51, 2018.

15. Frankel LB, Wen J, Lees M, Høyer-Hansen M, Farkas T, Krogh A, Jäättelä M and Lund AH: microRNA-101 is a potent inhibitor of autophagy. EMBO J 30: 4628-4641, 2011.

16. Valera E, Spencer B, Mott J, Trejo M, Adame A, Mante M, Rockenstein E, Troncoso JC, Beach TG, Masliah E and Desplats P: MicroRNA-101 modulates autophagy and oligodendroglial alpha-synuclein accumulation in multiple system atrophy. Front Mol Neurosci 10: 329, 2017.

17. Xu Y, An Y, Wang Y, Zhang C, Zhang H, Huang C, Jiang H, Wang $X$ and Li X: miR-101 inhibits autophagy and enhances cisplatin-induced apoptosis in hepatocellular carcinoma cells. Oncol Rep 29: 2019-2024, 2013.

18. National Research Council (US) Institute for Laboratory Animal Research: Guide for the Care and Use of Laboratory Animals. National Academies Press (US), Washington, DC, 1996.

19. National Research Council (US) Committee for the Update of the Guide for the Care and Use of Laboratory Animals: Guide for the Care and Use of Laboratory Animals. National Academies Press (US), Washington, DC, 2011.

20. Ji H, Shen X, Gao F, Ke B, Freitas MC, Uchida Y, Busuttil RW, Zhai Y and Kupiec-Weglinski JW: Programmed death-1/B7-H1 negative costimulation protects mouse liver against ischemia and reperfusion injury. Hepatology 52: 1380-1389, 2010.

21. Coleman MC, Olivier AK, Jacobus JA, Mapuskar KA, Mao G, Martin SM, Riley DP, Gius D and Spitz DR: Superoxide mediates acute liver injury in irradiated mice lacking sirtuin 3. Antioxid Redox Signal 20: 1423-1435, 2014.

22. Suzuki S, Toledo-Pereyra LH, Rodriguez FJ and Cejalvo D: Neutrophil infiltration as an important factor in liver ischemia and reperfusion injury. modulating effects of FK506 and cyclosporine. Transplantation 55: 1265-1272, 1993.

23. Livak KJ and Schmittgen TD: Analysis of relative gene expression data using real-time quantitative PCR and the 2(-Delta Delta C(T)) method. Methods 25: 402-408, 2001.

24. Vergne I, Roberts E, Elmaoued RA, Tosch V, Delgado MA, Proikas-Cezanne T, Laporte $\mathrm{J}$ and Deretic V: Control of autophagy initiation by phosphoinositide 3-phosphatase jumpy. EMBO J 28: 2244-2258, 2009. 
25. Zhou C,Zhong W,Zhou J, Sheng F,Fang Z, Wei Y, Chen Y, Deng X $\mathrm{Xia} B$ and Lin J: Monitoring autophagic flux by an improved tandem fluorescent-tagged LC3 (mTagRFP-mWasabi-LC3) reveals that high-dose rapamycin impairs autophagic flux in cancer cells. Autophagy 8: 1215-1226, 2012.

26. $\mathrm{Xu} \mathrm{C}, \mathrm{Yu} \mathrm{C}$ and $\mathrm{Li} \mathrm{Y}$ : Current studies on therapeutic approaches for ischemia/reperfusion injury in steatotic livers. Hepatol Res 38: 851-859, 2008.

27. Li CX, Ng KT, Shao Y, Liu XB, Ling CC, Ma YY, Geng W, Qi X, Cheng Q, Chung SK, et al: The inhibition of aldose reductase attenuates hepatic ischemia-reperfusion injury through reducing inflammatory response. Ann Surg 260: 317-328, 2014.

28. Ohsumi Y: Historical landmarks of autophagy research. Cell Res 24: 9-23, 2014.

29. Ohsumi Y: Molecular dissection of autophagy: Two ubiquitin-like systems. Nat Rev Mol Cell Biol 2: 211-216, 2001.

30. Weidberg H, Shpilka T, Shvets E, Abada A, Shimron F and Elazar Z: LC3 and GATE-16 N termini mediate membrane fusion processes required for autophagosome biogenesis. Dev Cell 20: 444-454, 2011

31. Li S, Zhang J, Wang Z, Wang T, Yu Y, He J, Zhang H, Yang T and Shen Z: MicroRNA-17 regulates autophagy to promote hepatic ischemia/reperfusion injury via suppression of signal transductions and activation of transcription-3 expression. Liver Transpl 22: 1697-1709, 2016.

32. Schneider JL and Cuervo AM: Liver autophagy: Much more than just taking out the trash. Nat Rev Gastroenterol Hepatol 11: 187-200, 2014

33. Shin CS and Huh WK: Bidirectional regulation between TORC1 and autophagy in saccharomyces cerevisiae. Autophagy 7: 854-862, 2011

34. Liu A, Huang L, Guo E, Li R, Yang J, Li A, Yang Y, Liu S, $\mathrm{Hu} \mathrm{J}$, Jiang $\mathrm{X}$, et al: Baicalein pretreatment reduces liver ischemia/reperfusion injury via induction of autophagy in rats. Sci Rep 6: 25042, 2016

35. Tan L, Jiang W, Lu A, Cai $\mathrm{H}$ and Kong L: miR-155 aggravates liver ischemia/reperfusion injury by suppressing SOCS1 in mice. Transplant Proc 50: 3831-3839, 2018.

36. Xiao Q, Ye QF, Wang W, Fu BQ, Xia ZP, Liu ZZ, Zhang XJ and Wang YF: Mild hypothermia pretreatment protects hepatocytes against ischemia reperfusion injury via down-regulating miR-122 and IGF-1R/AKT pathway. Cryobiology 75: 100-105, 2017.

37. Yang W, Chen J, Meng Y, Chen Z and Yang J: Novel targets for treating ischemia-reperfusion injury in the liver. Int J Mol Sci 19: E1302, 2018

38. Li SP, He JD, Wang Z, Yu Y, Fu SY, Zhang HM, Zhang JJ and Shen ZY: miR-30b inhibits autophagy to alleviate hepatic ischemia-reperfusion injury via decreasing the Atg12-Atg5 conjugate. World J Gastroenterol 22: 4501-4514, 2016.

39. Kim HJ, Joe Y, Yu JK, Chen Y, Jeong SO, Mani N, Cho GJ, Pae HO, Ryter SW and Chung HT: Carbon monoxide protects against hepatic ischemia/reperfusion injury by modulating the miR-34a/SIRT1 pathway. Biochim Biophys Acta 1852: $1550-1559,2015$

40. Wang G, Yao J, Li Z, Zu G, Feng D, Shan W, Li Y, Hu Y, Zhao $\mathrm{Y}$ and Tian $\mathrm{X}$ : miR-34a-5p inhibition alleviates intestinal ischemia/reperfusion-induced reactive oxygen species accumulation and apoptosis via activation of SIRT1 signaling. Antioxid Redox Signal 24: 961-973, 2016.

41. Vasudevan S, Tong Y and Steitz JA: Switching from repression to activation: microRNAs can up-regulate translation. Science 318: 1931-1934, 2007.

42. Carthew RW and Sontheimer EJ: Origins and Mechanisms of miRNAs and siRNAs. Cell 136: 642-655, 2009.

43. Siomi $\mathrm{H}$ and Siomi MC: On the road to reading the RNA-interference code. Nature 457: 396-404, 2009.
44. Lin CC, Liu LZ, Addison JB, Wonderlin WF, Ivanov AV and Ruppert JM: A KLF4-miRNA-206 autoregulatory feedback loop can promote or inhibit protein translation depending upon cell context. Mol Cell Biol 31: 2513-2527, 2011.

45. Vasudevan S and Steitz JA: AU-rich-element-mediated upregulation of translation by FXR1 and argonaute 2. Cell 128: 1105-1118, 2007.

46. Moshiri F, Salvi A, Gramantieri L, Sangiovanni A, Guerriero P, De Petro G, Bassi C, Lupini L, Sattari A, Cheung D, et al: Circulating miR-106b-3p, miR-101-3p and miR-1246 as diagnostic biomarkers of hepatocellular carcinoma. Oncotarget 9: 15350-15364, 2018.

47. Xu L, Beckebaum S, Iacob S, Wu G, Kaiser GM, Radtke A, Liu C, Kabar I, Schmidt HH, Zhang X, et al: MicroRNA-101 inhibits human hepatocellular carcinoma progression through EZH2 downregulation and increased cytostatic drug sensitivity. J Hepatol 60: 590-598, 2014.

48. Zhang S, Wang M, Li Q and Zhu P: MiR-101 reduces cell proliferation and invasion and enhances apoptosis in endometrial cancer via regulating PI3K/Akt/mTOR. Cancer Biomark 21: 179-186, 2017.

49. Saxton RA and Sabatini DM: mTOR signaling in growth, metabolism, and disease. Cell 168: 960-976, 2017.

50. Li Y, Wang S, Gao X, Zhao Y, Li Y, Yang B, Zhang N and Ma L: Octreotide alleviates autophagy by up-regulation of MicroRNA-101 in intestinal epithelial cell line caco-2. Cell Physiol Biochem 49: 1352-1363, 2018.

51. Cox LS: PCNA tightens its hold on the nucleus. Cell Cycle 14: 2727-2728, 2015

52. Melo RM, Martins YS, Luz RK, Rizzo E and Bazzoli N: PCNA and apoptosis during post-spawning ovarian remodeling in the teleost oreochromis niloticus. Tissue Cell 47: 541-549, 2015.

53. Ghavami S, Hashemi M, Ande SR, Yeganeh B, Xiao W, Eshraghi M, Bus CJ, Kadkhoda K, Wiechec E, Halayko AJ and Los M: Apoptosis and cancer: Mutations within caspase genes. J Med Genet 46: 497-510, 2009.

54. Nikoonahad Lotfabadi N, Mohseni Kouchesfahani H, Sheikhha MH and Kalantar SM: In vitro transfection of anti-tumor miR-101 induces BIM, a pro-apoptotic protein, expression in acute myeloid leukemia (AML). EXCLI J 16: 1257-1267, 2017.

55. Guertin DA and Sabatini DM: An expanding role for mTOR in cancer. Trends Mol Med 11: 353-361, 2005.

56. Kim J, Kim YC, Fang C, Russell RC, Kim JH, Fan W, Liu R, Zhong Q and Guan KL: Differential regulation of distinct Vps34 complexes by AMPK in nutrient stress and autophagy. Cell 152: 290-303, 2013

57. Kim J, Kundu M, Viollet B and Guan KL: AMPK and mTOR regulate autophagy through direct phosphorylation of Ulk1. Nat Cell Biol 13: 132-141, 2011

58. Liu D, Tang H, Li XY, Deng MF, Wei N, Wang X, Zhou YF, Wang DQ, Fu P, Wang JZ, et al: Targeting the HDAC2/HNF-4A/miR-101b/AMPK pathway rescues tauopathy and dendritic abnormalities in alzheimer's disease. Mol Ther 25: 752-764, 2017.

59. Liu P, Ye F, Xie X, Li X, Tang H, Li S, Huang X, Song C, Wei W and Xie X: mir-101-3p is a key regulator of tumor metabolism in triple negative breast cancer targeting AMPK. Oncotarget 7: 35188-35198, 2016

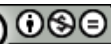

This work is licensed under a Creative Commons Attribution-NonCommercial-NoDerivatives 4.0 International (CC BY-NC-ND 4.0) License. 